\title{
Erratum to: Performance of the predatory mite Amblydromalus limonicus on factitious foods
}

Dominiek Vangansbeke $\cdot$ Duc Tung Nguyen $\cdot$
Joachim Audenaert $\cdot$ Ruth Verhoeven ·
Bruno Gobin $\cdot$ Luc Tirry $\cdot$ Patrick De Clercq

Published online: 25 February 2014

(C) International Organization for Biological Control (IOBC) 2014
$770.3 \pm 5.6,806.9 \pm 4.7$, and $839.3 \pm 5.4 \mu \mathrm{m}$ for T. latifolia, A. franciscana and E. kuehniella, resp. The erroneous values had no bearing on the final conclusions of the experiment.
The perimeters listed in Table 6 of the original publication were incorrect. They should have read
The online version of the original article can be found under doi:10.1007/s10526-013-9548-5.

D. Vangansbeke · D. T. Nguyen · L. Tirry · P. De Clercq $(\square)$

Laboratory of Agrozoology, Department of Crop Protection, Ghent University, Coupure Links 653, 9000 Ghent, Belgium

e-mail: Patrick.Declercq@ugent.be

D. Vangansbeke

e-mail: Dominiek.Vangansbeke@ugent.be

D. T. Nguyen

e-mail: Tung.NguyenDuc@ugent.be

L. Tirry

e-mail: Luc.Tirry@ugent.be
D. T. Nguyen

Hanoi University of Agriculture, Trau Quy, Gia Lam, Hanoi, Vietnam

J. Audenaert · R. Verhoeven · B. Gobin PCS-Ornamental Plant Research, Schaessestraat 18, 9070 Destelbergen, Belgium e-mail: Joachim.Audenaert@pcsierteelt.be

R. Verhoeven

e-mail: Ruth.Verhoeven@pcsierteelt.be

B. Gobin

e-mail: Bruno.Gobin@pcsierteelt.be 